\title{
Erratum to: Eunethydis: a statement of the ethical principles governing the relationship between the European group for ADHD guidelines, and its members, with commercial for-profit organisations
}

\author{
Joseph A. Sergeant - Tobias Banaschewski - Jan Buitelaar · David Coghill • Marina Danckaerts • \\ Manfred Döpfner · A. Rothenberger · Paramala Santosh · E. J. S. Sonuga-Barke • \\ Hans-Christoph Steinhausen $\cdot$ Eric Taylor $\cdot$ A. Zuddas
}

Published online: 15 August 2010

(C) Springer-Verlag 2010

\section{Erratum to: Eur Child Adolesc Psychiatry \\ DOI 10.1007/s00787-010-0114-8}

Jan Buitelaar's name was published incorrectly. The correct author list is given here.

The online version of the original article can be found under doi:10.1007/s00787-010-0114-8.

\section{J. A. Sergeant $(\bowtie)$}

Clinical Neuropsychology, Vrije Universiteit,

Amsterdam, The Netherlands

e-mail: JA.Sergeant@psy.vu.nl

\section{T. Banaschewski}

Department of Child and Adolescent Psychiatry

and Psychotherapy, Central Institute of Mental Health,

Mannheim, Germany

e-mail: tobias.banaschewski@zi-mannheim.de

J. Buitelaar

Donders Centrum, Rijksuniversiteit Nijmegen, Nijmegen,

The Netherlands

\section{Coghill}

Centre for Neuroscience, Division of Medical Sciences,

Ninewells Hospital and Medical School, University of Dundee,

Dundee DD1 9SR, UK

\section{Danckaerts}

Kliniekhoofd Kinder- en Jeugdpsychiatrie,

Clusterverantwoordelijke, UZ Leuven,

Campus Gasthuisberg, Herestraat 49, 3000 Leuven, Belgium

\section{Döpfner}

Department of Psychiatry and Psychotherapy of Childhood and Adolescence, University Cologne, Robert Koch Str. 10, 50931 Cologne, Germany

e-mail: manfred.doepfner@t-online.de

\section{A. Rothenberger}

Child and Adolescent Psychiatry, University of Goettingen,

von-Siebold-Str. 5, 37075 Göttingen, Germany

e-mail: arothen@gwdg.de

\section{P. Santosh}

Centre for Interventional Paediatric Psychopharmacology,

Great Ormond Street Hospital for Children, Level 4,

Frontage Building, London, UK

e-mail: santop@gosh.nhs.uk

\section{E. J. S. Sonuga-Barke}

School of Psychology, University of Southampton,

Southampton SO17 1BJ, UK

e-mail: ejb3@ soton.ac.uk

\section{E. J. S. Sonuga-Barke}

Department of Experimental Clinical \& Health Psychology,

Ghent University, Ghent, Belgium

H.-C. Steinhausen

Child and Adolescent Psychiatry, Aalborg Psychiatric Hospital, Aarhus University Hospital, MÃ slleparkvej.10,

9000 Aalborg, Denmark

e-mail: hces@rn.dk

URL: http://www.psykiatri.rn.dk

E. Taylor

King's College London Institute of Psychiatry,

De Crespigny Park, London SE5 8AF, UK

e-mail: e.taylor@iop.kcl.ac.uk

A. Zuddas

Child Neuropsychiatry, Department of Neuroscience,

University of Cagliari, Cagliari, Italy 